\title{
TOWARDS AN INVENTORY FOR ARCHAEOLOGICAL HERITAGE MANAGEMENT IN ISRAEL
}

\author{
Y. Alef \\ asrael Antiquities Authority, Nahalal 10600, P.O.B. 35 - yaelalef@gmail.com
}

KEY WORDS: Heritage Inventory, management, archaeological sites, GIS, conservation, significance assessment, risk assessment

\begin{abstract}
:
The vast amount of archaeological data and information that is systematically accumulated in the Israel Antiquities Authority database, has not yet been transformed into a tool for heritage management, i.e. accessible knowledge of the sites' cultural significance and risk assessment that is needed to support wise decision making regarding its future. As a response, a pilot project for developing an inventory for the archaeological heritage management was launched. A basic ESRI ArcGIS Online system was developed as a prototype, following the categories recommended in international standards for documentation. Five field surveys implementing the GIS system were conducted to examine different aspects and workflows: ancient synagogues in the Galilee, sites at risk, mosaics in Tel Shiqmona, the ancient settlement of Huqoq and sites included in The National Master Plan for Forests and Afforestation. The pilot project revealed the main gaps in knowledge and the critical faults in the working procedures. In spite of the systems' technological limitations, the results were convincing enough to promote a multidisciplinary discussion about the need for integration of significance and risk assessment in the working processes of the organization.
\end{abstract}

\section{INTRODUCTION}

A pilot project for developing an inventory for archaeological heritage management is taking place at the Israel Antiquities Authority (IAA) as part of a larger framework for establishing a national inventory for the built heritage that will include archaeological sites, historic buildings, urban and cultural landscapes.

The IAA archaeological database records information on 30,000 declared antiquity sites with basic data about the location, typology and periods of the remains, their excavations and publications and artefacts. Vast amounts of data have been gathered over the past century of archaeological research in the Land of Israel, and more systematically since 1964, in the Archaeological Survey of Israel. In addition, archaeological surveys in high resolution in smaller areas are conducted in response to development plans. The two types of surveys have yield to date 90,000 records of remains which are included in the declared antiquity sites (Sion, 2016). Conservation surveys, unlike archaeological surveys, have not yet been established as part of the systematic activity conducted by the IAA, and are only performed from time to time as an ad hoc response to specific planning needs. Up till now, information relating to the conservation of the sites has not been included in the databases and the archaeological knowledge has not yet been transformed into an inventory for the management of the archaeological heritage.

The archaeological information is gathered in the IAA database which is based on an ESRI system. Partial information is currently available for the public on the Archaeological Survey of Israel website ${ }^{1}$ which uses Microsoft system combined with Google maps. Currently the IAA is reassessing its different information systems with the intention to integrate them and provide better accessibility to the information.

\section{THE PILOT PROJECT}

\subsection{The Problem}

The issue of archaeological site conservation is complex because of the tension that exists between archaeological research on the one hand and the need to preserve the remains on the other. The archaeologist exposes the site, studies it and renders it value, while at the same time he destroys the remains during the excavation (Reich, 1987). However, the change in the archaeological management emphasis - from maximizing the potential research to preserving the remains in situ - requires a system for selecting and assessing archaeological sites for planning purposes. That is, distinguishing between an archaeological site and a heritage site; the difference stemming mainly from the value we attribute to the site and the future chosen for it. Heritage sites are those places we ascribe importance and choose to preserve and bequeath to future generations. To date however, cultural significance evaluation is not prepared as part of the archaeological report, there is no classification system for scheduling antiquities sites for conservation, or criteria for designation of archaeological reserves for future archaeological research. Most of the archaeological remains exposed in salvage excavations, for example, are not attributed the status of heritage sites, but are destroyed due to the development demands with no clear critical process.

This problem is related to the legal aspects, where, according to the Antiquities Law 1978, "antiquity" means any object which was made by man before the year $1700 \mathrm{CE}$, and "antiquity site" means an area which contains antiquities. The law provides extensive protection for antiquities (objects) but does not provide practical tools for identification, evaluation, protection and conservation of antiquity sites as cultural heritage sites for present and future generations.

Another problem is the lack of information on sites that were destroyed in excavations over the years. Salvage excavations,

\footnotetext{
${ }^{1}$ http://www.antiquities.org.il/survey/new/default_en.aspx
} 
which are conducted for the sake of development, are extremely destructive. The increase in the number of archaeological excavations in the country from a total of 2,200 excavations up to the 1990s, (Kletter \& De Groot, 2001) to 2,900 salvage excavations over the past decade (2004-2013), illustrates the problem of safeguarding archaeological reserves for the future. In fact, there are almost no large sites that have not been excavated in Israel, and dozens of smaller sites are being excavated every year and are 'erased' from the map. In this context we must ask, how much is 'rescued' in 'salvage' excavations? In any case, in the IAA database today, out of 30,000 declared antiquity sites, one has no indication which actually still exist and to what extent, and which have been totally lost.

In addition to the human threats induced by development, agricultural land use, looting etc. the IAA database does not contain any information regarding the threats to sites from environmental, geomorphological and biological factors, nor any information on the sites' physical state or risks.

\subsection{A Model for Heritage Management}

The criticism regarding salvage excavations resulted in seeking out new courses of action that would allow preserving as many sites as possible for the benefit of future research and use.

Lipe (1974) proposed a model for managing the archaeological heritage in the United States as a response to the problem posed by salvage excavations. This model is based on the understanding that archaeological research is predicated on an exhaustible resource that is rapidly being depleted. To slow down the depletion of the resource, Lipe calls on archaeologists to be involved in all aspects of archaeological resource management and proposes three courses of action:

1. Educating the Public - public support and promoting an appreciation for archaeology constitute the basis of the model. This is meant to prevent vandalism and create a social value by which archeology illuminates a cultural perspective of man's place in the world.

2. The Involvement of Archaeologists in Planning processes Lipe notes the absence of systematic planning-oriented surveys and inventories, as well as the importance of involvement in the planning stages and particularly in situations whereby salvage excavations are conducted after the fact, in a manner completely separated from planning.

3. Archaeological Reserves - a conservation strategy that seeks to safeguard the resource by designating "archaeological reserves". No zoning changes will be permitted in these reserves and they will subject to strict supervision. Over the years these principles have found expression in the archaeological heritage inventories of several countries around the world.

\subsection{Methodology}

The pilot project's methodology began with a preliminary study of heritage inventories and heritage data standards in order to characterize a prototype model. Those included the Arches system (Myers, Dalgity \& Avramides, 2016) and the heritage inventories in England (Carlisle \& Lee, 2016) the Council of Europe Core Data Index (Bold, 2009) and the CIDOC Conceptual Reference Model (ICOM 2015).

\footnotetext{
${ }^{2}$ http://www.cartadelrischio.it/

${ }^{3}$ English Heritage, Scheduled Monuments at Risk: http://www.english-heritage.org.uk/caring/heritage-atrisk/archaeology/scheduled-monuments-at-risk/
}

The main purpose at this stage was to understand what data is needed to inform decisions regarding three objectives:

1. protection, i.e. identification, classification and cultural significance assessment

2. conservation, i.e. interventions, physical condition, threats and risks

3. integration in development plans and presentation to the public, i.e. attractiveness and accessibility

The study found three stages in the development of heritage inventories, on top of the archaeological data that was collected: 1. Information for Planning Purposes - In the wake of recognizing the importance of integrating the archaeological sites in the planning processes in order to minimize destruction, while at the same time allowing the full cultural potential inherent in them, information for planning was added to heritage inventories, including a cultural significance assessment as well as information related to designation.

2. Information about the Risk Assessment of the site - the increasing awareness of risks to archaeological resources and their vulnerability to the environmental threats, air pollution, natural disasters, looting and destruction caused by armed conflicts, together with the conservation approaches that call for preventive conservation, have raised the need to acquire information and prepare for these risks. This approach is implemented in the Italian Cultural Heritage Risk Map Project that was inaugurated in $1992^{2}$ and the MEGA Jordan management system (D. Myers \& Dalgity, 2014), which focuses on identifying risks as a tool for monitoring, protecting and managing heritage. This is also the case regarding the list of Heritage at Risk in England, where for example it was found that $38 \%(!)$ of the designated sites had been damaged in 2013 by cultivation ${ }^{3}$.

3. Sharing Information and Public Awareness - Today, in the "Age of the Internet", the inventory of heritage sites also plays a central role in information sharing, education and raising public awareness. The Archaeological Survey of Israel website, is a basic example of this ${ }^{4}$. Among the current trends there are geographic information systems based on open source software, such as Arches Heritage Inventory and Management System ${ }^{5}$, designed with an emphasis on sharing of information functionalities, and adaptation for the specific needs of each inventory. Interactive systems, like the Los Angeles Historic Resources Survey ${ }^{6}$ based on the Arches system, even invite the public to propose new sites and share information about existing ones.

These categories were applied in a preliminary GIS system based on ESRI ArcGIS Online 'off the shelf' platform. This system was chosen in spite of its limitations, because it is already in use in the IAA in other applications and is familiar to the IT unit. In the second phase, five field surveys implementing the GIS system were conducted to examine different aspects and workflows. During the pilot project, interviews with various users in the IAA and other potential users were conducted in order to understand working process, needs and the state of existing data systems. This will be followed by a gap analysis and development of the inventory system.

\footnotetext{
${ }^{4} \mathrm{http} / / / \mathrm{www}$.antiquities.org.il/survey/new/

${ }^{5} \mathrm{https}: / /$ www.archesproject.org/

${ }^{6} \mathrm{http}: / /$ preservation.lacity.org/survey
} 


\subsection{The surveys}

1. A survey of ancient synagogues in the Galilee aimed at classifying management aspects in relation to physical condition and to identify sites at risk and potential stakeholders that could protect the sites (see fig.1).

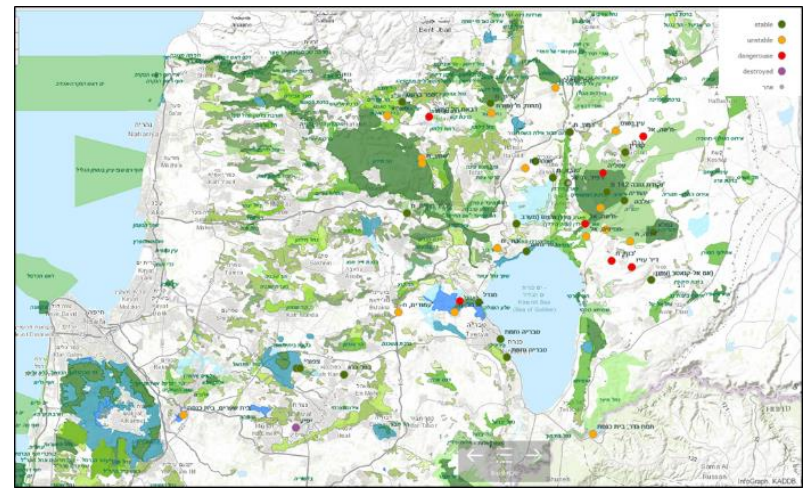

Figure 1. Distribution of ancient synagogues

according to the different stake holders in relation to their physical condition.

Of the 150 ancient synagogues that are known in the archaeological research (Levine, 1999), the conservation survey focused on approximately 60 sites where remains of a synagogue structure were identified in the field. The team that performed the survey included an archaeologist, conservator and architectural conservator. In the filed survey information about the condition of the site and its location was collected with ESRI Collector application. The additional data was uploaded to the system in the office. The survey findings reveal the following data:

a. Archaeological excavations: an archaeological survey was conducted at 19 of the sites. An excavation (extensive or partial) was carried out at 37 of the sites. In recent years two sites, Huqoq and Kur, are in the process of being uncovered.

b. The physical condition of the sites that were exposed in an excavation: at the two sites that are currently being exposed conservation interventions are being implemented concurrent with the excavation; however, at 16 sites, constituting about half of the synagogues that were exposed over the years, no conservation work has ever been done! (Fig. 2). Moreover, no permanent periodic conservation maintenance program is implemented at any of the sites.

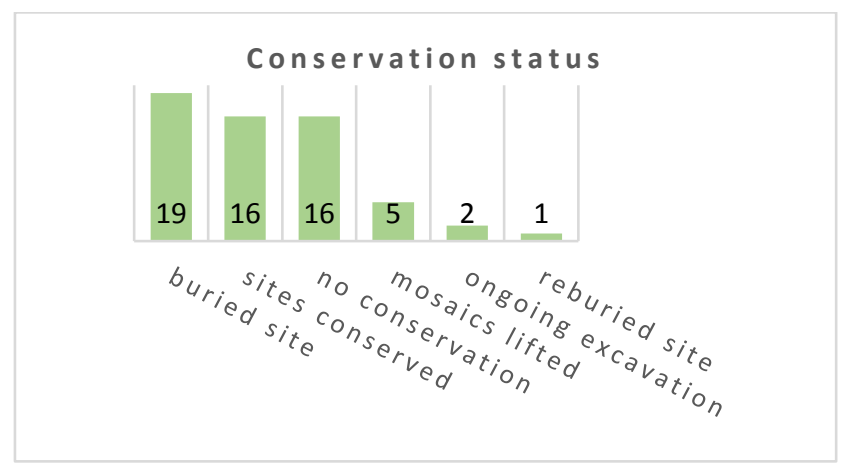

fig. 2. Conservation status distribution.

c. This data is consistent with the picture arising from the data on the physical condition of the sites. They indicate that about half of the sites are in a stable state (these are mostly sites that were not excavated and exposed), while half of them (most of the sites excavated) suffer from active deterioration and destructive processes causing structural instability and danger to the remains (Fig. 3). This is also true regarding the sites that have been conserved but have not been maintained, such as 'Ein Nashut, and over time deterioration has occurred requiring additional extensive "first aid" intervention. The intervention recommendations were formulated based on the sites' physical condition, their potential for display and identifying an agency that will assume responsibility for further treatment of the site.

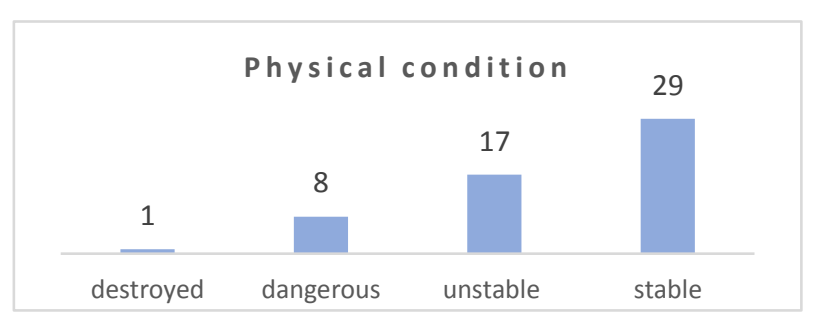

fig. 3. Physical condition distribution.

d. Custodians: About $40 \%$ of the sites, 25 of the 59, are located in areas of the Nature and Parks Authority, in national parks and nature reserves. At eight of these sites, the synagogue is the reason the site was declared a national park. Eleven sites are in areas managed by local authorities, the church and the Jewish National Fund (JNF), and the 23 other sites, constituting c. $40 \%$ of the total, remain to this day without any custodian being directly involved in their preservation (Fig. 4).

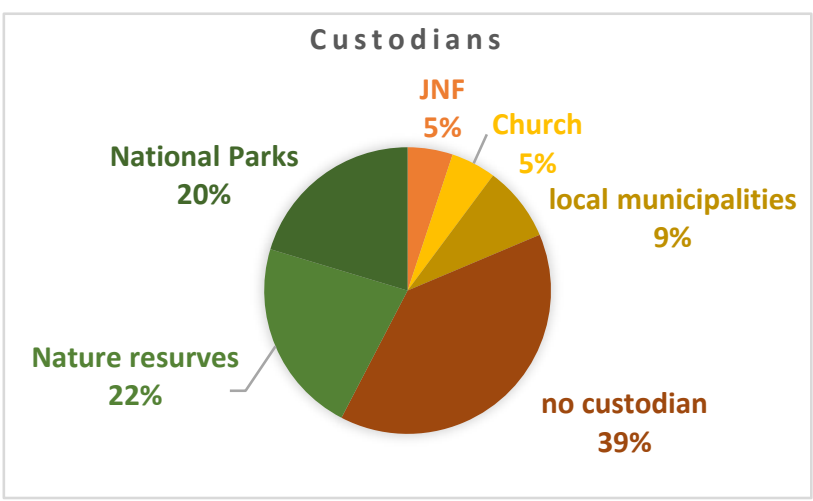

fig. 4. Distribution of custodians.

2. A survey of archaeological sites included in The National Master Plan for Forests and Afforestation all over the country, looked at management aspects and potential sites for conservation as part of development plans for forests (see fig. 5).

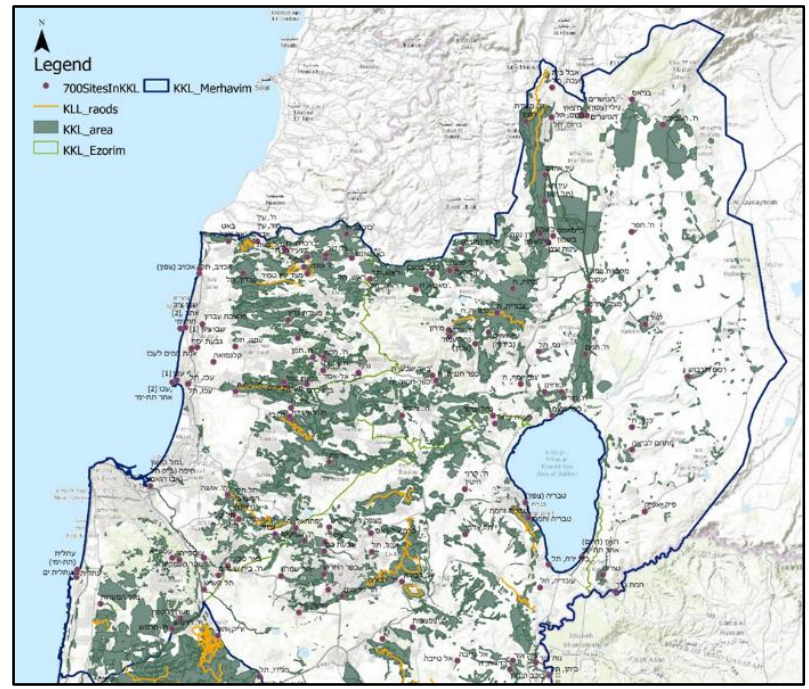

Figure 5. Compilation of forest scenic routs managed by the JNF and potential archaeological sites for conservation along the roads in the North District. 
3. A survey of sites at risk in the south district of Israel aimed at assessing site conditions in relation to resources as a basis for a regional conservation plan and treatment of the sites.

4. A survey of mosaics in the site of Tel Shiqmona was conducted to build the mosaic corpus of the site by locating mosaics that were lifted from the site, together with the in-situ mosaics, as a basis for a conservation plan (Fig. 6).

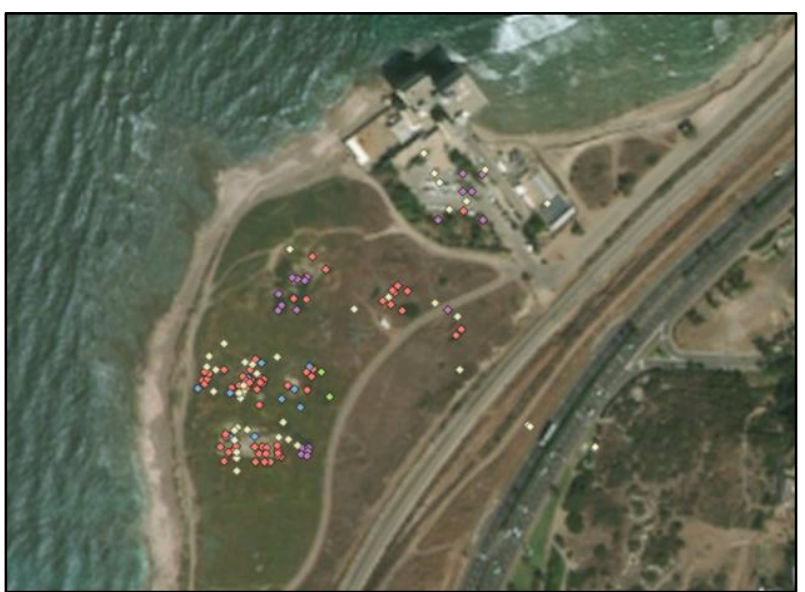

Figure 6. level of risks to mosaics in Tel Shiqmona.

5. An extensive survey of the ancient settlement of Hoquq as a cultural landscape, was conducted to understand aspects related to the significance in the process of preparing a master plan for a National Park and the planning of its presentation (see fig. 7).

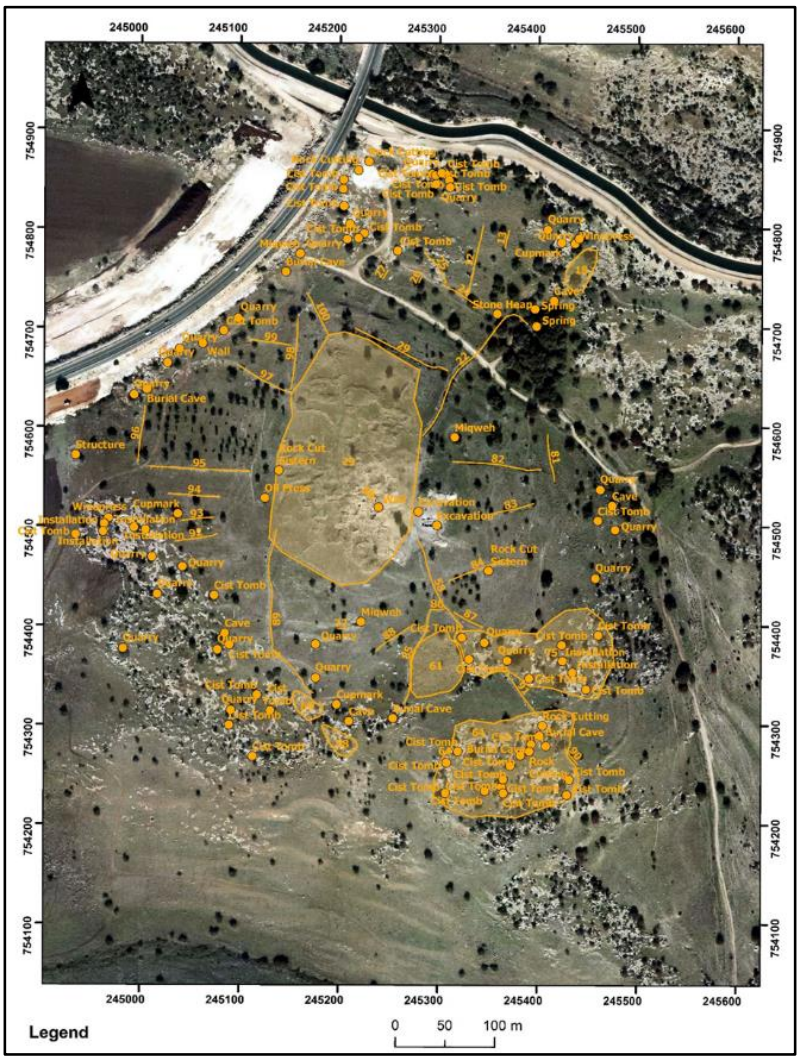

Figure 7. Archaeological survey as a basis for understanding the ancient landscape and site planning in $\mathrm{Kh}$. Hoquq

\section{CONCLUSIONS}

645 features all over the country, including elements such as mosaics, structures such as ancient synagogues and sites such as tels or ruins were collected to the system during the pilot project. This information was used for various purposes: risk preparedness plans for sites in the south and synagogues in the Galilee; documenting cultural landscape as a basis for a National Park master plan; mosaics inventory of a site that documents their original location and the current location of those that were lifted from the site.

The pilot project for a national archaeological inventory is part of an ongoing effort to shift the emphasis and work of the IAA from excavation and research to conservation and current heritage management approaches. Those place the GIS-based inventory at the centre of a model for the management and protection of archaeological heritage and particularly, the information required for development plans about the significance of the sites and the information required for conservation action plans about the threats and risks to the sites.

the project provided the IAA for the first-time, geospatial quantitative data regarding the conservation and management of the archaeological sites. This data was analysed and presented to decision makers to support informed decisions regarding allocation of budget, setting priorities for workplans of the conservation teams as well as potential collaboration with stakeholders.

Furthermore, the pilot revealed the main gaps in knowledge and the critical faults in working procedures in the IAA. In spite of the systems' technological limitations, the information that was gathered and the analysis that it enabled were convincing enough to promote a multidisciplinary discussion about the need for integration of significance and risk assessment in the working processes of the organization and to assigning resources for the next step of the development of the national inventory.

\section{AKNOWLEDGMENTS}

I would like to thank Zohar Ya'acobi form the IAA IT unit, Jacque Neguer and Avi Mashiah for allowing me to use the data from their surveys in Tel Shiqmona and the Sites at Risk in the South District Survey, Amit Rozenblum, Oren Zingboim, Uri Berger and Shua Kisilevich for their help in our experimental field surveys in the Golan, upper Galilee and Kh Hoquq.

\section{REFERENCES}

Bold, J. (Ed). 2009. Guidance on inventory and documentation of the cultural heritage. Strasbourg: Council of Europe Publ.

Carlisle, P., \& Lee, E. 2016. Recording the past: heritage inventories in England. In Journal of Cultural Heritage Management and Sustainable Development. 6(2):128-137

ICOM. 2015. CIDOC Conceptual Reference Model. Retrieved June 2017. http://www.cidoc-crm.org/Version/version-6.2

Kletter, R., \& De-Groot, A. 2001. Excavating to Excess? Implications of the Last Decade of Archaeology in Israel. Journal of Mediterranean Archaeology, 14(1), 76-85.

Levine L. I. 1999. The Ancient Synagogue: The First Thousand Years. New Haven/London: Yale University Press. 
Lipe W.D. 1974. A Conservation Model for American Archaeology. Kiva 39(3/4):213-245.

Myers, D, Dalgity, A. \& Avramides, I. 2016. The Arches heritage inventory and management system: a platform for the heritage field. Journal of Cultural Heritage Management and Sustainable Development, Vol. 6 Issue: 2, pp.213-224, https://doi.org/10.1108/JCHMSD-02-2016-0010

Reich R. 1987. The Archaeologist's Dilemma: On Some Aspects of Archaeology as a "Destructive" Scientific Discipline. Old Cultures in New Worlds. Eighth ICOMOS General Assembly and International Symposium. Program Report - Compte Rendu (1009-1015) Washington:

US/ICOMOS. Retrieved:

http://international.icomos.org/publications/wash133.pdf

Sion, O., 2016. Personal communication. 